\title{
Advances in the role of sacral nerve neuromodulation in lower urinary tract symptoms
}

\author{
Philip E. V. Van Kerrebroeck
}

Published online: 23 October 2010

(C) The Author(s) 2010. This article is published with open access at Springerlink.com

\begin{abstract}
Sacral neuromodulation has been developed to treat chronic lower urinary tract symptoms, resistant to classical conservative therapy. The suspected mechanisms of action include afferent stimulation of the central nervous system and modulation of activity at the level of the brain. Typical neuromodulation is indicated both in overactivity and in underactivity of the lower urinary tract. In the majority of patients, a unilateral electrode in a sacral foramen and connected to a pulse generator is sufficient to achieve significant clinical results also on long term. In recent years, other urological indications have been explored.
\end{abstract}

Keywords Lower urinary tract symptoms (LUTS) - Sacral neuromodulation $\cdot$ Bladder pacemaker

\section{Introduction}

Chronic types of lower urinary tract dysfunction, including urge incontinence, urgency-frequency (both included in the overactive bladder syndrome or OAB together eventually with nocturia) and non-obstructive urinary retention, still present a therapeutic challenge. Most patients are initially treated with conservative therapies including bladder retraining, pelvic floor exercises, and biofeedback. In the majority of patients, this standard regimen is supported with pharmacological therapy (anticholinergics). However, approximately $40 \%$ either do not achieve an acceptable level of therapeutic benefit or remain completely refractory to treatment. Alternative surgical procedures such as bladder transsection, transvesical phenol injection of the

P. E. V. Van Kerrebroeck $(\bowtie)$

Department of Urology, University Hospital Maastricht, P.O. Box 5800, 6202 AZ Maastricht, The Netherlands

e-mail: pvk@suro.azm.nl pelvic plexus, augmentation cystoplasty, and even urinary diversion have been advocated for these chronic conditions. However, these procedures have variable efficacy and have been associated with significant morbidity and risk. Therefore, research into the use of electrical current for the treatment of lower urinary tract dysfunction has been initiated.

In 1878, Saxtorph reported intravesical electrostimulation in patients with a contractile bladder and complete urinary retention [1]. He inserted a special catheter with a metal electrode transurethrally. After him, Katona, Ascoli, and Federici applied electrostimulation in patients with chronic neurogenic retention and hyperreflexia $[2,3]$. In the field of urology, electric currents were and are used particularly in the bladder, the pelvic floor muscles, and the sacral roots [4-6]. A publication by Nashold et al. in 1971 reported on a successful implantation of a neural prosthesis in the sacral segment of the spinal cord [7]. The implant was used to activate voiding in a patient with spinal cord injury. Jonas and Tanagho tried to improve this prosthesis because during stimulation not only the bladder contracted but the urinary sphincter as well [8, 9]. Later Tanagho and Schmidt demonstrated that the stimulation of sacral root S3 generally modulates detrusor and sphincter action and could be used in clinical practice [10-13]. After two decades of experimentation with sacral root stimulation, finally in October of 1997, sacral neuromodulation for treatment of refractory urge incontinence was approved by the Food and Drug Administration in the United States. More than 25,000 patients underwent sacral nerve stimulation (SNS) since the FDA approval.

\section{Mechanism of action}

The stimulation of afferent nerve fibers by electrical current modulates reflex pathways involved in the filling and 
evacuation phase of the micturition cycle through spinal circuits mediating somato-visceral interactions within the sacral spinal cord. SNS is proposed to activate or "reset" the somatic afferent inputs that play a pivotal role in the modulation of sensory processing and micturition reflex pathways in the spinal cord $[14,15]$. Because beneficial effects can be demonstrated at intensities of stimulation that do not activate movements of striated muscle, the afferent system is the most likely effected [16].

Urinary retention and dysfunctional voiding can be resolved by inhibition of the guarding reflexes. Detrusor overactivity can be suppressed by one or more pathways, i.e., direct inhibition of bladder preganglionic neurons, as well as inhibition of interneuronal transmission in the afferent limb of the micturition reflex [15].

Recent research with PET scanning indicates that at the level of the brain, the activity of centers in the paraventricular grey involved in activation or inhibition of the micturition reflex, can be enhanced or reduced by sacral nerve stimulation and results in up- or downgrading of lower urinary tract activity [17-19]. Blok et al. reported on the acute and chronic effects of SNS for urge incontinence on the brain. They registered differences between newly and chronically implanted patients in brain areas involved in sensory and motor learning. No differences were seen in regional cerebral blood flow (rCBF) in areas that are part of the micturition reflex. Changes in rCBF were seen in specific areas: areas known to be involved in micturition and areas involved in awareness and awakeness. Acute SNS modulates sensorimotor learning areas and these become less active during chronic SNS [20].

\section{Selecting patients for SNS}

All patients who have symptoms of voiding dysfunction and who cannot be helped by other measures should be considered for SNS. Patient selection begins with a careful history, physical examination, routine urine tests, and, very important, the voiding diaries. Voiding diaries are a valuable instrument during the selection and have to be filled in carefully. Urodynamics are used to identify the patients with detrusor overactivity with or without urinary leakage or urinary retention. Koldewijn et al. studied predictors of success in 100 test stimulation patients and did not find any [21]. Scheepens et al. studied the data from 211 patients who underwent a trial stimulation (percutaneous nerve evaluation [PNE]) to determine the clinical parameters that can enhance the prediction of PNE success. They found that intervertebral disk prolapse, duration of complaints, neurogenic bladder dysfunction, and urge incontinence were found to be significant predictive factors. However, a PNE remains necessary to evaluate a patient's chance of permanent implant success objectively [22].

Cohen et al. recently published a study on motor versus sensory response. They concluded that a good motor response during implantation was a predictive factor (in $95 \%$ of successfully treated patients) for success while a sensory response was not. All these patients were implanted under local anesthesia but with intravenous sedation and therefore the sensory perception of these patients may be unreliable [23].

Although not clearly reported before, it is known that a substantial part of the patients selected for SNS therapy have a history of psychological dysfunction and/or sexual abuse in the past. Weil et al. reported that special attention is needed for this group of patients [24]. They noted that patients with a history of psychological disorders, who had a good response during temporary test stimulation, had a far greater chance of lack of maintaining effect after permanent implantation. Of these patients, $82 \%$ showed a poor result after definitive implantation compared to $28 \%$ of the patients without a history of psychological disorders. Besides this lack of effect, $25 \%$ of the reoperations was done in this group, most of them with no effect. Psychological testing or psychiatric evaluation in case of doubt was advised before implantation of a permanent system.

A study by Everaert et al. showed similar findings [25]. In this study, the two-stage procedure was compared with the single-stage procedure. In the two-stage implant group, there were no failures during the first stage, while in the single-stage procedure, three patients had an immediate failure. They suggested that these results might be strongly influenced by psychological factors. Mental disorders were not related to objective or subjective success but these cofactors surely interfere with symptomatology and therewith co-influencing the results of therapy.

During the MDT-103 trial (to get the FDA approval) in 89 patients, depression and health-related quality of life (HRQOL) were assessed [26]. Patients were divided in a direct implant group and a delayed implant group. At baseline, they noted detectable levels of depression in $73 \%$ of all patients. After 3 months, patients in the implanted group had a significant improvement in depression scores. These improved scores remained at the 6- and 12-month visits. The scores on the SF-36 questionnaire, a questionnaire to investigate pain, vitality, physical functioning, social functioning, and mental health, increased in the implant group for role physical, pain, and social functioning. This study demonstrated the serious impact that unresolved voiding dysfunction has on quality of life. SNS was associated with significant improvement in depression and HRQOL. 


\section{Technique of sacral neuromodulation}

Although sacral neuromodulation is planned as a long-term treatment, the therapy incorporates a unique temporary test stimulation procedure that allows patients and physicians to assess sacral nerve stimulation over a trial period [27]. Results of the trial are used by the physician to evaluate the viability of a permanent surgical implant. This test stimulation is conducted as an outpatient procedure preferably under local anesthetic and comprises of two steps, acute testing and the home evaluation phase. This testing phase is used to be performed as a PNE test in an outpatient clinic setting. The original technique was described by Schmidt et al. and is a simple procedure to evaluate the effect of sacral neuromodulation [27]. A test needle is inserted into the third sacral foramen to stimulate the sacral root. Lead migration is a known complication of this test, other complications are technical failures or pain [28]. Some patients who fail a PNE test are still good candidates for SNS therapy. For these reasons, a two-stage implant technique was developed [29]. With this technique, a permanent electrode is implanted and connected to an external stimulator. Less lead migration and a longer test period made it possible for clinicians to separate nonresponders from technical failures. Using this two-stage implant technique, eight out of ten patients who failed a PNE test had a good result with SNS therapy and were implanted with a permanent system. A less invasive technique in combination with a newly designed selfanchoring lead made it possible to test patients with this two-stage technique $[30,31]$. This "tined lead" has four sets of self-anchoring tines, which made a minimally invasive percutaneous placement possible, performed under local anesthesia, requiring no additional incision and no additional anchoring. Besides these advantages, this way of implantation made it possible to test the sensitive responses during implantation and it resulted in a reduction of operating time. The "tined lead" staged implant technique is nowadays widely used in Europe and the US [32].

The acute phase is used to test the neural integrity and therefore, sensory and motor responses should be obtained during this test. The motor responses are important to identify the right sacral root. Typical S3 stimulation results in bellows movement of the pelvic floor, plantar flexion of the great toe, and paraesthesia in the rectum, perineum, scrotum, or vagina. Stimulation of the other sacral roots results in different motor responses: S2 gives clamp movement or twisting and pinching of the anal sphincter plantar flexion of the entire foot, lateral rotation; S4 stimulation results in bellows motion of the pelvic floor, no lower extremity activity, and a sensation of pulling in the rectum [33].
The manual method to localize the S3 foramen is more difficult for obese patients or those without palpable landmarks. Alternatively, fluoroscopy can be used for S3 localization. More importantly, the use of lateral imaging helps to determine the depth required for implanting the S3 lead. The use of fluoroscopic localization of S3 allowed the introduction of tined S3 lead and transformed the placement of a lead from an open procedure to a completely percutaneous one [30,31]. The widely adopted percutaneous use of a tined lead approach abandoned the need for fixation of the lead by methods such as bone anchors.

So nowadays implantation of SNS consists of two steps. First, a test phase which involves the placement of a stimulation lead next to the dorsal root of S3 for a test period between 1-4 weeks. Home evaluation affords the patient an opportunity to feel the stimulation and enables the physician to assess the effects of therapy on the voiding variables. If the patient's symptoms under the existing list of indications for SNS improve at least more than $50 \%$ then the patient is a candidate to undergo the stage II or permanent step in which the permanent implantable pulse generator (IPG) unit is implanted in the soft tissue of the buttock of the patient.

During the second stage, the implanted tined lead is connected to the implantable pulse generator with a connecting cable that is passed subcutaneously. Relatively low amplitudes $(0-3.0 \mathrm{~V})$ are sufficient for stimulation of the somatic nerve fibers and to minimize the potential for nerve damage due to overstimulation. Within the recommended stimulation parameters $(210 \mu \mathrm{S}, 10-16 \mathrm{~Hz})$, continuous stimulation is possible without pain sensation.

\section{Unilateral or bilateral stimulation}

Although temporary and chronic SNS can result in significant permanent clinical improvement, some patients improve only partially or temporarily [34, 35]. For these patients, several methods have been developed to improve the results [30-32]. The most widely accepted method to test a patient for SNS therapy is unilateral stimulation. In some clinics, bilateral stimulation has been suggested as a method to obtain better results [36, 37]. The bilateral innervation of the bladder is the basis for this type of intervention [38, 39]. Animal studies were performed to find a scientific basis for the application of bilateral neuromodulation. Animal studies by Schultz-Lampel et al. suggest that bilateral sacral neuromodulation can be a more effective technique for voiding dysfunction [40]. They conclude that bilateral stimulation may be more effective at lower stimulation intensities with positive side effects as longer stimulator-battery life and less potential nerve damage. 
The only prospective randomized crossover trial to compare unilateral approach with bilateral sacral nerve stimulation is performed by Scheepens et al. [41]. In this study, 33 patients with chronic voiding dysfunction underwent unilateral as well as bilateral test stimulation to assess the possible advantages of bilateral stimulation. All patients were stimulated during at least $72 \mathrm{~h}$ in a unilateral and a bilateral setting with a washout period of at least $48 \mathrm{~h}$ between these two test periods. Standardized voiding records were used, and urine was measured using standard measuring cups. They analyzed results for 12 patients with urge incontinence and for 13 patients with non-obstructive urinary retention. They did not find any significant differences comparing the results for unilateral with bilateral stimulation. Although two patients of the retention group started voiding during bilateral stimulation, during unilateral stimulation they were still in complete retention. The reason for this remarkable result could be that with bilateral stimulation sufficient sacral nerve afferents are stimulated to achieve marked effect at central level.

In conclusion, unilateral stimulation should be performed before bilateral sacral stimulation is considered. However, a bilateral test stimulation could be indicated when a unilateral test fails [41, 42]. Further research with clinical follow-up could identify suitable patients for bilateral sacral nerve stimulation.

\section{Clinical results and complications of SNS}

In 1999, a prospective randomized study was published which evaluated the results of SNS therapy for urge incontinence (UI) were evaluated [43]. In total, 76 patients were treated in a multicenter trial; 34 patients were implanted and received chronicle stimulation for 6 months; after these 6 months, they completed a therapy evaluation test (on versus off), 42 patients in a delay group were treated with standard medical therapy for 6 months and were offered implantation after this period. After 6 months, the number of daily incontinence episodes, the number of daily replaced diapers, and the severity of incontinence was significantly reduced in the stimulation group. In the stimulation group, 16 patients $(47 \%)$ were completely dry and ten patients (29\%) showed a greater than $50 \%$ reduction in incontinence episodes. After 18 months, the efficacy appeared to be sustained. During the therapy evaluation at 6 months, the stimulation group returned to baseline symptoms when stimulation was stopped.

Hassouna et al. reported in 2000 on the treatment of urgency-frequency (UF) symptoms with SNS therapy [44]. In total 51 patients, a stimulation group of 25 patients and a control group of 26 patients enrolled in this multicenter trial. All these patients had been tested with a PNE test and showed satisfactory responses. The stimulation group was implanted directly after this test, the control group was implanted after 6 months delay period. Statistically significant improvements were seen in the stimulation group for diary parameters as: number of voids daily $(16.9 \pm 9.7-9.3 \pm$ $5.1)$, volume per void $(118 \pm 74-226 \pm 124 \mathrm{ml})$, and degree of urgency (rank 2.2 $\pm 0.6-1.6 \pm 0.9$ ). In the control group, no significant changes were seen. After 6 months, the stimulation group had an evaluation test and urinary symptoms returned to baseline when stimulation was turned off. After reactivation of the stimulation, sustained efficacy was seen at 12 and 24 months.

A report of use of SNS in urinary retention was published in 2001 by Jonas et al. One hundred seventyseven patients with urinary retention refractory to conservative therapy were enrolled in this multicenter trial between 1993 and 1998 [45]. Thirty-seven patients were assigned to treatment and 31 to the control group. At 6 months, the stimulation group showed $69 \%$ elimination of catheterization and an additional 14\% with greater than $50 \%$ reduction in catheter volume per catheterization. Temporary inactivation (3 days) of SNS therapy resulted in significant increase in residual volume. The effectiveness of SNS therapy was sustained for 18 months after implantation. The first long-term follow-up results of the above-mentioned patient series were published in 2000 [28]. Results were reported for 1.5 to 3 years of follow-up. Of 41 UI patients, $59 \%$ showed a greater than $50 \%$ reduction in leaking episodes with $46 \%$ of these patients being completely dry after 3 years. After 2 years of follow-up, $56 \%$ of the UF patients showed a greater than $50 \%$ reduction in voids per day. In the retention group, $70 \%$ of 42 patients showed a greater than $50 \%$ reduction in catheter volume per catheterization.

Recently, the 5-year follow-up results of patients included in the trial, in order to get FDA approval, were analyzed. Of 163 patients enrolled, 152 have been implanted. Of the 152 implanted patients, 96 (63.2\%) had UI, 25 (16.4\%) UF, and $31(20.4 \%)$ retention. Voiding diaries were collected annually over 5 years. For UI patients, the mean number of leaking episodes per day declined from $9.6 \pm 6.0$ to $3.9 \pm 4.0$. For UF patients, mean voids per day decreased from $19.3 \pm 7.0$ to $14.8 \pm$ 7.6. Mean volume voided per void increased from $92.3 \pm 52.8$ to $165.2 \pm 147.7 \mathrm{ml}$. No life-threatening or irreversible adverse events occurred. Of 152 patients, 102 experienced 33 devicerelated and 246 therapy-related adverse events. At 5 years, $68.0 \%$ of UI, $56.0 \%$ of UF, and $71.0 \%$ of retention patients had successful outcomes. However, an important finding in this study is the high correlation between the 1- and 5-year success rates. Of the implanted patients, $84 \%$ with UI, $71 \%$ with UF, and $78 \%$ with retention continued to have a successful outcome at 5-year follow-up if successful at 1 year [46]. Different clinics have published their long-term results in the previous years 
[47-49]. They all conclude SNS therapy is a safe and effective therapy.

All the above-mentioned studies reported on complications during SNS. Siegel et al. summarized the complications in patients with refractory urge incontinence, urgency-frequency, and urinary retention that were included in the original trials of SNS [28]. The complications were divided in PNE-related complications and implant-related problems. Of the 914 test stimulation procedures done on the 581 patients, 181 adverse events occurred in 166 of these procedures $(18.2 \%$ of the 914 procedures). The vast majority of complications were related to lead migration (108 events, $11.8 \%$ of procedures). Technical problems and pain represented $2.6 \%$ and $2.1 \%$ of the adverse events. For the 219 patient who underwent implantation of the permanent system, the following adverse events were seen during follow-up: pain at neurostimulator site $(15.3 \%)$, new pain $(9 \%)$, suspected lead migration $(8.4 \%)$, transient electric shock $(5.5 \%)$, pain at lead site $(5.4 \%)$, adverse change in bowel function $(3.0 \%)$, and some less frequent events like technical problems, device problems, change in menstrual cycle, and others. Surgical revisions of the implanted neurostimulator or lead system were performed in $33.3 \%$ of cases ( 73 of 219 patients) to resolve an adverse event. Mostly, this was done to relocate the stimulator because of pain or because of suspected lead migration. No serious adverse events, side effects, or permanent injury was reported.

Recently our long-term follow-up results with complication rates were published [47]. Of 149 patients analyzed, 107 had overactive bladder symptoms and 42 had urinary retention. Mean follow-up was $64.2(\mathrm{SD}=38.5)$ months. In the whole group, 194 adverse events occurred. Six patients had infection in their implanted system, one was explanted for infection. Most events could be solved by giving advice or by reprogramming the stimulator. One hundred twentynine reoperations have been performed and 21 patients had their system explanted. Analysis of the data shows a striking difference in the incidence of reoperations, but small differences in subjective results in the groups of patients implanted before or after 1996, suggesting that a proactive approach towards adverse events is worthwhile. In our experience with the tined lead implantation, we see a clear decrease in reoperation rate [50]. Of 39 patients implanted with the tined lead, Voskuilen et al. described seven severe adverse events on medium term, three of these needed a reoperation. Three patients could be treated with one or two reprogramming sessions. Three patients had a reoperation to reposition the IPG after complaints of pain. These three patients had good results afterwards. One patient with an incomplete spinal cord lesion has no benefit of the implanted system.

Of 161 patients implanted with the tined lead between July 2002 and September 2004, Hijaz et al. described the complications seen in their institute [51]. They had three categories for complications: infections, mechanical problems, and response-related dysfunction. In total, they reported 17 explantations(10.5\%). Eight explantations were done due to infection and seven due to loss of effect. In 26 (16.1\%) patients, they performed a revision after these patients presented with a decrease in clinical response. The reasons for revision were: mechanical (lead) problems, IPG site discomfort, lead migration, and infectious causes. These complication rates show a decrease over the years mainly due to technical and procedural improvements. Gaynor-Krupnick et al. as well as Hijaz and Vasada presented an algorithm for evaluation and managing of a malfunctioning neuromodulation system $[52,53]$.

\section{Expanding indications}

With the widespread use, incidental improvements were published for other pathological conditions. Use of SNS for other off-label applications has been reported for treatment of interstitial cystitis, chronic pelvic pain, pediatric voiding dysfunction, and neurogenic lower urinary dysfunction seen in multiple sclerosis.

In 2000, the first papers were published with positive results with the use of SNS in interstitial cystitis [54, 55]. Comiter evaluated the effect of SNS therapy for interstitial cystitis in a prospective study in 2003 [56]. Seventeen out of 25 patients were implanted with a permanent system. After a mean follow-up of 14 months, there were significant improvements in daytime frequency and nocturia improved from 17.1 to 8.7 and 4.5 to 1.1 , respectively $(p<0.01)$. Mean voided volume increased from 111 to $264 \mathrm{ml}(p<0.01)$. Average pain score decreased from 5.8 to 1.6 points on a scale of 0 to $10(p<0.01)$. Interstitial cystitis symptom and problem index scores decreased from 16.5 to 6.8 and 14.5 to 5.4 , respectively $(p<0.01)$.

Chronic pelvic pain or genitourinary pain is a hard to treat condition. Over the years, some cases were presented of patients implanted with a SNS system for these conditions. In 2001, Siegel et al. implanted ten patients with a permanent system [57]. After 9 months of follow-up, nine of ten patients had a decrease in most severe pain scores; after a median follow-up of 19 months, six out of ten patients reported significant improvement in pain symptomatology.

After the clinical implication of SNS therapy for voiding dysfunction, Matzel together with Schmidt and Tanagho started to investigate SNS therapy in bowel dysfunction $[58,59]$. In a prospective non-randomized multicentre study, 37 patients underwent test stimulation with SNS therapy for fecal incontinence [60]. Thirty-four patients were implanted with a permanent system. The effect on incontinence was assessed by daily bowel habit diaries and 
a disease-specific quality of life questionnaire. The frequency of incontinent episodes per week decreased from 16.4 to 3.1 at 12 months and to 2.0 at 24 months for both urge and passive incontinence. The mean number of incontinence episodes per week, staining, and pad use declined significantly too. Quality of life improved significantly in ASCRS scales; in the SF-36 scales only social functioning improved significantly.

Jarrett et al. did a systematic review of SNS for fecal incontinence and constipation [61]. They reported total continence in $41-75 \%$ of the patients, $75-100 \%$ experienced improvement in the incontinence symptoms. The results for patients treated with SNS for constipation discussed in this review seem promising but limited data is available by this time.

The results of SNS therapy in children with neurogenic bladder dysfunction is described by Guys et al. [62]. In total, 42 children with neurogenic bladder dysfunction, mainly due to spina bifida, enrolled in this prospective randomized controlled trial. Twenty-one patients were treated conservatively, while the other 21 patients were treated with SNS therapy. After 12 months, no significant better results were seen in the group treated with SNS. The authors stated that probably the intervention group was too small or the bladder dysfunction in these patients too severe.

\section{Sexuality}

During routine follow-up, patients may report improved sexual functioning after implant. Pauls et al. recently reported a pilot study to determine if sacral neuromodulation has an effect on the patient's subsequent sexual function [63]. Eleven patients with a permanent system implanted were questioned about their sexual function before and after implantation. With SNS therapy, sexual frequency and female sexual function index (FSFI) increased significantly. No correlation was found between improvement in urinary symptoms and FSFI scores.

\section{Conclusions}

After years of experimental therapy, initiated by Tanagho and Schmidt, sacral nerve stimulation is nowadays a widely used therapy. Although the mechanism for this therapy is still not fully understood, the therapy has been proven effective on the long term. Due to the less invasive technique and other technical improvements, it is expected that complication rates will further decrease within the coming years. The expanding use of SNS therapy in fields other than urology will probably result in FDA approval for gastrointestinal indications.
Further research, possible with the help of animal models, has to be performed to understand in a more precise way the mechanism of SNS therapy. Other goals in research could be: patient selection (finding ways to identify more appropriate candidates), the effect of sacral neuromodulation in combined (urology-gynecology-GI) pathology, the effect of bilateral versus unilateral stimulation.

Conflicts of interest The author is advisor and lecturer for Medtronic Inc.

Open Access This article is distributed under the terms of the Creative Commons Attribution Noncommercial License which permits any noncommercial use, distribution, and reproduction in any medium, provided the original author(s) and source are credited.

\section{References}

1. Madersbacher H (1999) Conservative therapy of neurogenic disorders of micturition. Urologe Ausg 38(1):24-29

2. Katona F (1975) Stages of vegatative afferentation in reorganization of bladder control during intravesical electrotherapy. Urol Int 30(3):192-203

3. Ascoli R (1965) Treatment of neurogenic bladder. Acta Urol Belg 33:76-83

4. Boyce WH, Lathem JE, Hunt LD (1964) Research related to the development of an artificial electrical stimulator for the paralyzed human bladder: a review. J Urol 91:41-51

5. Dees JE (1965) Contraction of the urinary bladder produced by electric stimulation. Preliminary report. Invest Urol 15:539-547

6. Boyce WH, Lathem E, Hunt LD (1963) Research related to the development of an artificial electrical stimulator for the paralyzed human bladder: a review. Trans Am Assoc Genitourin Surg 55:81-91

7. Nashold BS Jr, Friedman H, Boyarsky S (1971) Electrical activation of micturition by spinal cord stimulation. J Surg Res 11(3): 144-147

8. Jonas U, Heine JP, Tanagho EA (1975) Studies on the feasibility of urinary bladder evacuation by direct spinal cord stimulation. I. Parameters of most effective stimulation. Invest Urol 13(2):142150

9. Jonas U, Tanagho EA (1975) Studies on the feasibility of urinary bladder evacuation by direct spinal cord stimulation. II. Poststimulus voiding: a way to overcome outflow resistance. Invest Urol 13 (2): $151-153$

10. Schmidt RA, Bruschini H, Tanagho EA (1979) Sacral root stimulation in controlled micturition. Peripheral somatic neurotomy and stimulated voiding. Invest Urol 17(2):130-134

11. Tanagho EA, Schmidt RA (1988) Electrical stimulation in the clinical management of the neurogenic bladder. J Urol 140 (6):1331-1339

12. Tanagho EA, Schmidt RA, Orvis BR (1989) Neural stimulation for control of voiding dysfunction: a preliminary report in 22 patients with serious neuropathic voiding disorders. J Urol $142(2$ Pt 1):340-345

13. Tanagho EA, Schmidt RA (1982) Bladder pacemaker: scientific basis and clinical future. Urology 20(6):614-619

14. Fall M, Lindstrom S (1991) Electrical stimulation. A physiologic approach to the treatment of urinary incontinence. Urol Clin North Am 18(2):393-407

15. Leng WW, Chancellor MB (2005) How sacral nerve stimulation neuromodulation works. Urol Clin North Am 32(1):11-18 
16. Vodusek DB, Light JK, Libby JM (1986) Detrusor inhibition induced by stimulation of pudendal nerve afferents. Neurourol Urodyn 5(4):381-389

17. Blok BF, Groen J, Veltman D, Bosch R (2003) and L. A., brain plasticity and urge incontinence: PET studies during the first hours of sacral neuromodulation. Neurourol Urodyn 22:490-491

18. Blok BF (2002) Central pathways controlling micturition and urinary continence. Urology 59(5 Suppl 1):13-17

19. Dasgupta R, Critchley HD, Dolan RJ, Fowler CJ (2005) Changes in brain activity following sacral neuromodulation for urinary retention. J Urol 174(6):2268-2272

20. Bosch JL (2006) Electrical neuromodulatory therapy in female voiding dysfunction. BJU Int 98(Suppl 1):43-48

21. Koldewijn EL, Rosier PF, Meuleman EJ, Koster AM, Debruyne FM, van Kerrebroeck PE (1994) Predictors of success with neuromodulation in lower urinary tract dysfunction: results of trial stimulation in 100 patients. J Urol 152(6 Pt 1):2071-2075

22. Scheepens WA, Jongen MM, Nieman FH, de Bie RA, Weil EH, van Kerrebroeck PE (2002) Predictive factors for sacral neuromodulation in chronic lower urinary tract dysfunction. Urology 60 (4):598-602

23. Cohen BL, Tunuguntla HS, Gousse A (2006) Predictors of success for first stage neuromodulation: motor versus sensory response. J Urol 175(6):2178-2180, discussion 2180-2181

24. Weil EH, Ruiz-Cerda JL, Eerdmans PH, Janknegt RA, Van Kerrebroeck PE (1998) Clinical results of sacral neuromodulation for chronic voiding dysfunction using unilateral sacral foramen electrodes. World J Urol 16(5):313-321

25. Everaert K, Kerckhaert W, Caluwaerts H, Audenaert M, Vereecke H, De Cuypere G, Boelaert A, Van den Hombergh U, Oosterlinck W (2004) A prospective randomized trial comparing the 1-stage with the 2-stage implantation of a pulse generator in patients with pelvic floor dysfunction selected for sacral nerve stimulation. Eur Urol 45(5):649-654

26. Das AK, Carlson AM, Hull M (2004) Improvement in depression and health-related quality of life after sacral nerve stimulation therapy for treatment of voiding dysfunction. Urology 64(1):62-68

27. Schmidt RA, Senn E, Tanagho EA (1990) Functional evaluation of sacral nerve root integrity. Report of a technique. Urology 35 (5):388-392

28. Siegel SW, Catanzaro F, Dijkema HE, Elhilali MM, Fowler CJ, Gajewski JB, Hassouna MM, Janknegt RA, Jonas U, van Kerrebroeck PE, Lycklama a Nijeholt AA, Oleson KA, Schmidt RA (2000) Long-term results of a multicenter study on sacral nerve stimulation for treatment of urinary urge incontinence, urgency-frequency, and retention. Urology 56(6 Suppl 1):87-91

29. Janknegt RA, Weil EH, Eerdmans PH (1997) Improving neuromodulation technique for refractory voiding dysfunctions: twostage implant. Urology 49(3):358-362

30. Spinelli M, Giardiello G, Arduini A, van den Hombergh U (2003) New percutaneous technique of sacral nerve stimulation has high initial success rate: preliminary results. Eur Urol 43(1):70-74

31. Spinelli M, Giardiello G, Gerber M, Arduini A, van den Hombergh U, Malaguti S (2003) New sacral neuromodulation lead for percutaneous implantation using local anesthesia: description and first experience. J Urol 170(5):1905-1907

32. Spinelli M, Weil E, Ostardo E, Del Popolo G, Ruiz-Cerda JL, Kiss G, Heesakkers J (2005) New tined lead electrode in sacral neuromodulation: experience from a multicentre European study. World J Urol 23(3):225-229

33. Daneshgari F (2006) Applications of neuromodulation of the lower urinary tract in female urology. Int Braz J Urol 32(3):262-272

34. Bosch JL, Groen J (2000) Sacral nerve neuromodulation in the treatment of patients with refractory motor urge incontinence: long-term results of a prospective longitudinal study. J Urol 163 (4):1219-1222
35. Weil EH, Ruiz-Cerda JL, Eerdmans PH, Janknegt RA, Bemelmans BL, van Kerrebroeck PE (2000) Sacral root neuromodulation in the treatment of refractory urinary urge incontinence: a prospective randomized clinical trial. Eur Urol 37(2):161-171

36. Braun PM, Sief C, Scheepe JR, Martinez Portillo FJ, Bross S, Alken P, Junemann KP (2002) Chronic sacral bilateral neuromodulation. Using a minimal invasive implantation technique in patients with disorders of bladder function. Urologe Ausg 41(1):44- 47

37. Hohenfellner M, Schultz-Lampel D, Dahms S, Matzel K, Thuroff JW (1998) Bilateral chronic sacral neuromodulation for treatment of lower urinary tract dysfunction. J Urol 160(3 Pt 1):821-824

38. Ingersoll EH, Jones LL, Hegre ES (1957) Effect on urinary bladder of unilateral stimulation of pelvic nerves in the dog. Am J Physiol 189(1):167-172

39. Diokno AC, Davis R, Lapides J (1973) The effect of pelvic nerve stimulation on detrusor contraction. Invest Urol 11(3):178-181

40. Schultz-Lampel D, Jiang C, Lindstrom S et al (1998) Neurophysiologische Effekte unilateraler und bilateraler sakraler Neuromodulation. Aktuelle Urol 29:354-360

41. Scheepens WA, de Bie RA, Weil EH, van Kerrebroeck PE (2002) Unilateral versus bilateral sacral neuromodulation in patients with chronic voiding dysfunction. J Urol 168(5):2046-2050

42. van Kerrebroeck EV, Scheepns W, de Bie RA, Weil EH (2005) European experience with bilateral sacral neuromodulation in patients with chronic lower urinary tract dysfunction. Urol Clin North Am 32(1):51-57

43. Schmidt RA, Jonas U, Oleson KA, Janknegt RA, Hassouna MM, Siegel SW, van Kerrebroeck PE (1999) Sacral nerve stimulation for treatment of refractory urinary urge incontinence. Sacral nerve stimulation study group. J Urol 162(2):352-357

44. Hassouna MM, Siegel SW, Nyeholt AA, Elhilali MM, van Kerrebroeck PE, Das AK, Gajewski JB, Janknegt RA, Rivas DA, Dijkema H, Milam DF, Oleson KA, Schmidt RA (2000) Sacral neuromodulation in the treatment of urgency-frequency symptoms: a multicenter study on efficacy and safety. J Urol 163(6):1849-1854

45. Jonas U, Fowler CJ, Chancellor MB, Elhilali MM, Fall M, Gajewski JB, Grunewald V, Hassouna MM, Hombergh U, Janknegt R, van Kerrebroeck PE, Nijeholt AA Lylcklama a, Siegel SW, Schmidt RA (2001) Efficacy of sacral nerve stimulation for urinary retention: results 18 months after implantation. J Urol 165 (1):15-19

46. van Kerrebroeck $P$, van Voskuilen A, Lycklama a Nijeholt AA, Dijkema H, Bemelmans B, Fall M, Fowler C, Das A, Milam D, Siegel S, Van Den Hombergh U, P.S. Group (2004) Long-term results of Interstim therapy for voiding disorders demonstrate sustained efficacy and acceptable safety profile. Eur Urol Supp 2(3):170

47. van Voskuilen AC, Oerlemans DJ, Weil EH, de Bie RA, van Kerrebroeck PE (2006) Long term results of neuromodulation by sacral nerve stimulation for lower urinary tract symptoms: a retrospective single center study. Eur Urol 49(2):366-372

48. Elhilali MM, Khaled SM, Kashiwabara T, Elzayat E, Corcos J (2005) Sacral neuromodulation: long-term experience of one center. Urology 65(6):1114-1117

49. Dasgupta R, Wiseman OJ, Kitchen N, Fowler CJ (2004) Long-term results of sacral neuromodulation for women with urinary retention. BJU Int 94(3):335-337

50. van Voskuilen A, Oerlemans DJ, Weil EH, Van Den Hombergh U, van Kerrebroeck P (2007) Medium-term experience of sacral neuromodulation by tined lead implantation. BJU Int 99:107-110

51. Hijaz A, Vasavada SP, Daneshgari F, Frinjari H, Goldman H, Rackley R (2006) Complications and troubleshooting of two-stage sacral neuromodulation therapy: a single-institution experience. Urology 68(3):533-537

52. Gaynor-Krupnick DM, Dwyer NT, Rittenmeyer H, Kreder KJ (2006) Evaluation and management of malfunctioning sacral neuromodulator. Urology 67(2):246-249 
53. Hijaz A, Vasavada S (2005) Complications and troubleshooting of sacral neuromodulation therapy. Urol Clin North Am 32 (1):65-69

54. Chai TC, Zhang C, Warren JW, Keay S (2000) Percutaneous sacral third nerve root neurostimulation improves symptoms and normalizes urinary HB-EGF levels and antiproliferative activity in patients with interstitial cystitis. Urology 55(5):643-646

55. Zermann DH, Weirich T, Wunderlich H, Reichelt O, Schubert J (2000) Sacral nerve stimulation for pain relief in interstitial cystitis. Urol Int 65(2):120-121

56. Comiter CV (2003) Sacral neuromodulation for the symptomatic treatment of refractory interstitial cystitis: a prospective study. J Urol 169(4):1369-1373

57. Siegel S, Paszkiewicz E, Kirkpatrick C, Hinkel B, Oleson K (2001) Sacral nerve stimulation in patients with chronic intractable pelvic pain. J Urol 166(5):1742-1745

58. Matzel KE, Schmidt RA, Tanagho EA (1990) Neuroanatomy of the striated muscular anal continence mechanism. Implications for the use of neurostimulation. Dis Colon Rectum 33(8):666-673
59. Matzel KE, Stadelmaier U, Hohenfellner M, Gall FP (1995) Electrical stimulation of sacral spinal nerves for treatment of faecal incontinence. Lancet 346(8983):1124-1127

60. Matzel KE, Kamm MA, Stosser M, Baeten CG, Christiansen J, Madoff R, Mellgren A, Nicholls RJ, Rius J, Rosen H (2004) Sacral spinal nerve stimulation for faecal incontinence: multicentre study. Lancet 363(9417):1270-1276

61. Jarrett ME, Mowatt G, Glazener CM, Fraser C, Nicholls RJ, Grant AM, Kamm MA (2004) Systematic review of sacral nerve stimulation for faecal incontinence and constipation. Br J Surg 91(12):1559-1569

62. Guys JM, Haddad M, Planche D, Torre M, Louis-Borrione C, Breaud J (2004) Sacral neuromodulation for neurogenic bladder dysfunction in children. J Urol 172(4 Pt 2):16731676

63. Pauls RN, Marinkovic SP, Silva WA, Rooney CM, Kleeman SD, Karram MM (2007) Effects of sacral neuromodulation on female sexual function. Int Urogynecol J Pelvic Floor Dysfunct 18:391395 